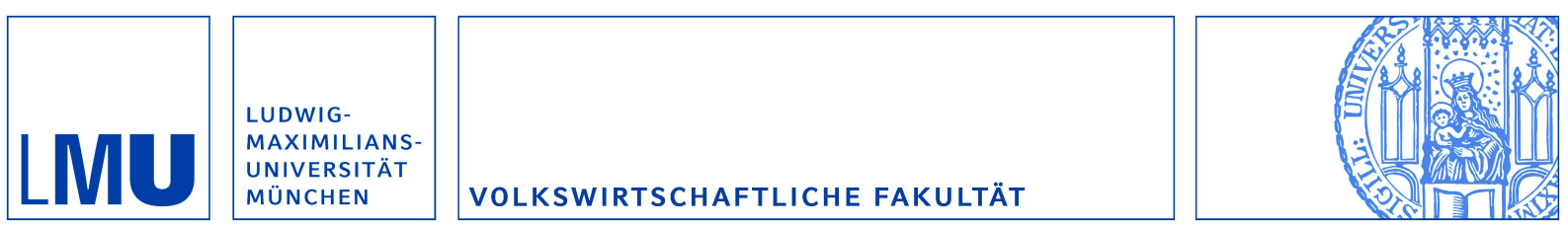

Kajuth, Florian und Watzka, Sebastian:

Inflation expectations from index-linked bonds:

Correcting for liquidity and inflation risk premia

Munich Discussion Paper No. 2008-13

Department of Economics

University of Munich

Volkswirtschaftliche Fakultät

Ludwig-Maximilians-Universität München

Online at https://doi.org/10.5282/ubm/epub.4858 


\title{
Inflation expectations from index-linked bonds: Correcting for liquidity and inflation risk premia
}

\author{
Florian Kajuth* Sebastian Watzka ${ }^{\dagger \ddagger}$ \\ Ludwig-Maximilians-Universität Munich \\ Department of Economics
}

July 2008

\begin{abstract}
We provide a critical assessment of the method used by the Cleveland Fed to correct expected inflation derived from index-linked bonds for liquidity and inflation risk premia and show how their method can be adapted to account for time-varying inflation risk premia. Furthermore, we show how sensitive the Cleveland Fed approach is to different measures of the liquidity premium. In addition we propose an alternative approach to decompose the bias in inflation expectations derived from index-linked bonds using a state-space estimation. Our results show that once one accounts for time-varying liquidity and inflation risk premia current 10-year U.S. inflation expectations are lower than estimated by the Cleveland Fed.
\end{abstract}

Keywords: Inflation expectations, liquidity risk premium, inflation risk premium, treasury inflation-protected securities (TIPS), state-space model

JEL Classification: E31, E52, G12

*florian.kajuth@lrz.uni-muenchen.de

†sebastian.watzka@lrz.uni-muenchen.de

${ }^{\ddagger}$ We would like to thank Gerhard Illing for motivating us to study the topic and for very stimulating discussions. We would also like to thank Tara Sinclair and participants at the Macro Seminar at the LMU Department of Economics for helpful comments and suggestions. All errors are of course our own responsibility. 


\section{Introduction}

In 1997 the U.S. government started to issue a ten-year inflation-linked bond, a treasury inflationprotected security (TIPS) ${ }^{1}$. Inflation linked bonds make it possible to observe the real interest rate and furthermore allow to infer the so-called break-even inflation rate (BEIR), which is the difference between the nominal and real yield of a security with the same characteristics such as the same maturity. The BEIR is a market based measure of expected inflation and is in many ways preferable to survey based measures. However, the yield on a nominal bond contains a premium for the risk that inflation changes unexpectedly, which leads the BEIR to overstate inflation expectations ceteris paribus. Conversely, the yield on an inflation-linked bond probably contains a premium for liquidity risk, which results in an understatement of inflation expectations when looking at the BEIR ceteris paribus. Therefore it is essential that one correctly adjusts the BEIR for both premia. The Federal Reserve Bank of Cleveland publishes an adjusted measure for expected inflation each month. For May 2008 the Cleveland Fed puts expected inflation after adjustment for liquidity and inflation risk premia at 3.2 percent.

In this paper we provide a critical assessment of the method the Cleveland Fed uses to adjust for liquidity and inflation risk premia. We show how their method can be adapted to account for time-varying inflation risk premia and provide estimates of expected inflation that correct for a variable inflation risk premium. In addition, we question their measure of the liquidity premium and show that using an alternative measure yields different results for current inflation expectations. Furthermore, we propose an alternative method based on a state-space approach to correct BEIRs for both risk premia without recurring to survey based measures of expected inflation. Our results show that both modifications of the Cleveland Fed method result in considerably lower values for U.S. ten-year expected inflation.

The paper is structured as follows. Section 2 provides a critical assessment of the Cleveland Fed approach. In section 3 we adapt the Fed-method to include a time-varying inflation risk premium and present new estimates of the adjusted measure for expected inflation. Section 4 looks in more detail at the liquidity premium in the TIPS market. Section 5 sets up our proposed state-space model of nominal yields, real yields and expected inflation and presents estimation results for the adjusted values for expected inflation. Finally section 6 concludes.

\footnotetext{
${ }^{1}$ TIPS are linked to the urban not-seasonally adjusted U.S. CPI. For a comprehensive introduction to indexlinked bonds in the Euro Area see Garcia and van Rixtel (2007).
} 


\section{Criticism of the Cleveland Fed approach}

The method used by the Cleveland Fed aims at explaining the difference between the unadjusted measure of expected average annual inflation over the next 10 years $^{2}$, which is the difference $i_{t}^{T-b i l l}-r_{t}^{T I P S}$ and often called break-even inflation rate (BEIR), and the unbiased expected average annual inflation, $E_{t} \bar{\pi}_{t, t+10}$. Note that the observed nominal T-bill yield is equal to the unobserved natural real rate $r_{t}$ plus expected inflation $E_{t} \bar{\pi}_{t, t+10}$ and an inflation risk premium $\rho_{t}^{\pi}$.

$$
i_{t}^{T-b i l l}=r_{t}^{T I P S}+E_{t} \bar{\pi}_{t, t+10}+\rho_{t}^{\pi}
$$

and the real yield from TIPS is equal to the unobserved natural real rate plus a liquidity risk premium $\rho_{t}^{L P}$.

$$
r_{t}^{T I P S}=r_{t}+\rho_{t}^{L P}
$$

The Fisher equation states that

$$
i_{t}^{T-b i l l}=r_{t}^{T I P S}+E_{t} \bar{\pi}_{t, t+10}+\rho_{t}^{\pi}-\rho_{t}^{L P}
$$

where $\rho_{t}^{\pi}$ is an inflation risk premium and $\rho_{t}^{L P}$ is a liquidity risk premium. Define in (3)

$$
\begin{aligned}
\text { Spread }_{t} & \equiv i_{t}^{T-\text { bill }}-r_{t}^{T I P S}-E_{t} \bar{\pi}_{t, t+10} \\
& =B E I R_{t}-E_{t} \bar{\pi}_{t, t+10} \\
& =\rho_{t}^{\pi}-\rho_{t}^{L P}
\end{aligned}
$$

To get a measure for the spread the Cleveland Fed takes the 10-year CPI-inflation expectations from the Survey of Professional Forecasters (SPF) as an unbiased estimator for $E_{t} \bar{\pi}_{t, t+10}$. As shown in equation (6), the spread contains both a liquidity premium and an inflation risk premium. The inflation risk premium is expected to lead to an overstatement of inflation expectations, while the liquidiy premium to an understatement. The Cleveland Fed assumes the inflation risk premium constant, $\rho_{t}^{\pi}=\rho^{\pi}$, and assumes the liquidity premium in the yield of inflation-linked bonds to be correlated with the liquidity premium for nominal bonds of the

\footnotetext{
${ }^{2}$ The method is documented at http://www.clevelandfed.org/research/data/tips/index.cfm [13 May 2008].
} 
same maturity. To quantify the liquidity premium in nominal bonds the Cleveland Fed uses the difference between the yield on off-the-run and on-the-run nominal 10-year treasury bills:

$$
L P_{t}=i_{t}^{o f f}-i_{t}^{o n}
$$

On-the-run securities of a particular maturity are the most recently issued ones. Once a new set of securities with the same original maturity are issued, the former ones become offthe-run. Since on-the-run securities are considered to be more liquid than off-the-run ones, they command a premium over off-the-run ones, which results in a lower yield ${ }^{3}$. Regressing the spread on a constant and the linear and squared measure of the liquidity premium in the nominal bond market the Cleveland Fed arrives at the following equation:

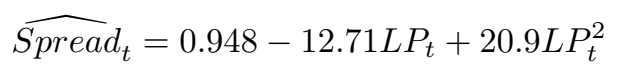

As expected the constant inflation risk premium biases the BEIR away from actual expected inflation and the liquidity premium narrows the spread, however at a decreasing rate. The squared term is meant to capture the idea that investors don't like uncertainty about liquidity conditions. However, an increase in uncertainty from a relatively low level weighs more than the same increase in uncertainty from a relatively high level. Unfortunately, there is no information on the sample period used. Using this result the Fed then calculates an adjusted measure for expected inflation by subtracting the spread from the BEIR.

$$
E_{t} \pi_{t, t+10}^{a d j}=B E I R_{t}-0.948+12.71 L P_{t}-20.9 L P_{t}^{2}
$$

In our opinion there are three major problems with this method. The first is that the method uses survey data for expected inflation as an unbiased estimator for actual expected inflation. However, the aim should really be to get away from survey based measures and use nominal and real yields as market measures to get an estimate of actual expected inflation. Moreover, a survey based measure might not be unbiased either. Let's however assume that the SPF expected inflation is truly unbiased and that one could account for all the bias in the BEIR. Then one should be able to compute a perfectly adjusted measure for expected inflation at daily frequency, the quarterly average of which should - on average - yield the SPF expected inflation again. ${ }^{4}$ A detailed analysis of this point is provided in the appendix. Thus, the only advantage gained

\footnotetext{
${ }^{3}$ For a detailed account of how primary market dealers use on-the-run securities in their business see Fisher (2002). Vayanos and Weill (2006) propose a theory for why on-the-run securities come to be more liquid than off-the-run ones.

${ }^{4}$ The SPF inflation forecast is available at quarterly frequency only.
} 
would be an unbiased measure for expected inflation at daily frequency, which however would flucutuate around the SPF expected inflation. At a 10-year horizon one would then give probably more weight to the SPF expected inflation because of its lower frequency, rendering the adjusted series redundant.

Now, in contrast, assume the SPF forecast is biased. Then the method is flawed because it is based on a faulty measure of the spread, which then additionally contains the survey bias. Therefore it would be desirable to carry out the adjustment for the biases without referring to survey based measures at all. We propose an alternative method based on a simple state-space approach in section 5 .

Our second objection is that the relationship between the liquidity premia in the TIPS market and the liquidity premia on the nominal bond market might not be as stable as assumed by the Fed. In particular, it is widely argued (e.g. Shen, 2006; Sack and Elsasser, 2004) that the TIPS market has gained a reasonable degree of liquidity only over the last couple of years. Thus, we argue the liquidity premium in the TIPS yields relative to the nominal treasuries yields is not free of any trending patterns, be they deterministic or stochastic. The problem with stochastic trends and univariate regression analysis is of course the possibility of spurious results. Moreover, aside from econometric issues regarding the liquidity premium there might be a problem with using the on-/off-the-run spread $L P_{t}$ as a measure for $\rho_{t}^{L P}$. Consider the period from August 2007 to today. It is likely that markets experienced the so-called flight to quality, where investors increase their holdings of safe treasury papers and reduce their holdings of risky papers. This would depress the nominal bonds yield. To the extent that the off-the-run yield decreases by less than the on-the-run yield $L P_{t}$ rises. However, the change in $L P_{t}$ is obviously not related to a change in the liquidity in the TIPS market. On the contrary, TIPS liquidity is even likely to increase as trading volume increases because demand for TIPS increases due to fears of inflation and inflation risk. Data for the transactions volume in the TIPS market confirm this conjecture. As a consequence the TIPS liquidity premium hasn't increased by as much and adjusted inflation expectations didn't rise as much as in the Fed approach.

Finally, we argue that it is implausible to assume a constant inflation risk premium. A priori it is not obvious why the inflation risk bias should be constant over time. Inflation volatility is particularly high in times of high inflation. Because it is intuitive to relate the inflation risk premium to inflation volatility, it follows that we should allow for a variable inflation risk premium. If what we want to model are the dynamic properties of inflation expectations - and if these properties are not constant - then one should allow for inflation volatility and hence let 
inflation risk premia change with expectations about the level of inflation itself ${ }^{5}$.

Furthermore, the outlook for future inflation might become more uncertain during times of economic and financial turbulance, such as the recent episode of financial distress during the past months. Even if one was to look at inflation expectations over the next ten years as a gauge for the credibility of monetary policy, then this judgement could become more uncertain as central banks are faced with new problems for which no established response exists. Moreover a number of studies have found considerable variability in an estimated inflation risk premium (see references in Amico, Kim and Wei, 2008). Therefore we correct for this shortcoming and argue that to correctly model inflation expectations one needs to take into account a variable inflation risk premium.

The next section adapts the Cleveland Fed method by including a time-varying inflation risk premium. In section4 we provide some empirical evidence on the relation between liquidity premia in the TIPS market and the market for nominal Treasuries.

\section{Correcting for a time-varying inflation risk premium}

In this section we extend the analysis by the Cleveland Fed and allow for a time-varying inflation risk premium, which the Cleveland Fed assumes constant. In particular we estimate the following equation.

$$
\text { Spread }_{t}=\beta_{0}+\beta_{1} L P_{t}+\beta_{2} L P_{t}^{2}+\beta_{3} I P_{t}+\varepsilon_{t}
$$

where Spread $_{t}$ is defined as in (5), $L P_{t}$ defined in (7) and $I P_{t}$ is a measure for the inflation risk premium, and $\varepsilon_{t}$ is assumed normally distributed whited noise. Daily data for $\operatorname{spread}_{t}$ and $L P_{t}$ are taken from the Cleveland Fed homepage and run from 3/2/1997 to 28/3/2008. There are two measures for the inflation risk premium. One is the standard deviation of individual forecasts of inflation from the SPF. The higher the dispersion of the individual forecasts the more uncertain are the survey participants and the higher should be the inflation risk premium. This measure however is only available quarterly and we have taken the quarterly value to be valid on each day of the month. The second measure is the estimated volatility of actual inflation from a GARCH(1,1) model. The higher the volatility of actual inflation the higher the uncertainty in estimating expected inflation, and therefore the higher the inflation risk premium.

We estimated three different versions of (10) on the whole sample. One with $\beta_{3}=0$ as a

\footnotetext{
${ }^{5}$ For a detailed analysis of inflation risk premia in European bond yields see e.g. Hördahl and Tristani (2007).
} 
Spread $_{t}=\beta_{0}+\beta_{1} L P_{t}+\beta_{2} L P_{t}^{2}+\beta_{3} I P_{t}+\varepsilon_{t}$

Sample period $3 / 2 / 1997$ to $28 / 3 / 2008$

\begin{tabular}{l|cccc} 
Version & $\beta_{0}$ & $\beta_{1}$ & $\beta_{2}$ & $\beta_{3}$ \\
\hline \hline$I$ & $0.53^{* * *}$ & $-8.46^{* * *}$ & $12.45^{* * *}$ & - \\
$I I$ & $0.68^{* * *}$ & $-8.86^{* * *}$ & $13.46^{* * *}$ & $-0.29^{* * *}$ \\
$I I I$ & $0.24^{* * *}$ & $-7.29^{* * *}$ & $10.32^{* * *}$ & $0.50^{* * *}$
\end{tabular}

Table 1: Estimation results for different versions of the spread equation. Three asterisks denote significance on the $1 \%$-level.

comparison to what the Cleveland Fed did (version $I$ ), one with the volatility of the SPF forecast as measure for $I P_{t}$ (version $I I$ ), and one with the estimated volatility of actual inflation as a measure for $I P_{t}$ (version $I I I$ ). Subsequently we adjusted the raw BEIR series by subtracting the spread. The results are summarized in table 1 and plotted in figure 1.

Table 1 shows that the three versions yield plausible signs for the coefficients of all variables except the coefficient on the standard deviation of the individual forecast from the SPF. The inflation risk premium is expected to lead to an overestimation of the spread, which seems not confirmed by version II of the regression. However, the coefficient on the conditional volatility of inflation as a measure for inflation risk yields the expected sign. All coefficients are significant on the $1 \%$-level.

Figure 1 plots the different results for expected inflation over the next ten years for the period $1 / 1 / 2007$ to $28 / 3 / 2008$ along with the SPF forecast. First thing to notice is that the Cleveland Fed series differs considerably from our estimated version $I$, which is supposed to replicate the Fed results. Obviously, the Fed does not include all available data points in their estimation. Instead they appear to have estimated the spread equation on a subsample. Our results, however, show that including all data up to the present yields a lower current value for expected inflation even without correcting for inflation risk. Furthermore, replacing the constant with a time-varying measure for the inflation risk premium leads to markedly different values for expected inflation.

Figure 2 shows that in particular from the third quarter 2007 to the end of sample adjusted inflation expectations are up to 23 basis points lower when accounting for a time-varying inflation risk premium. 


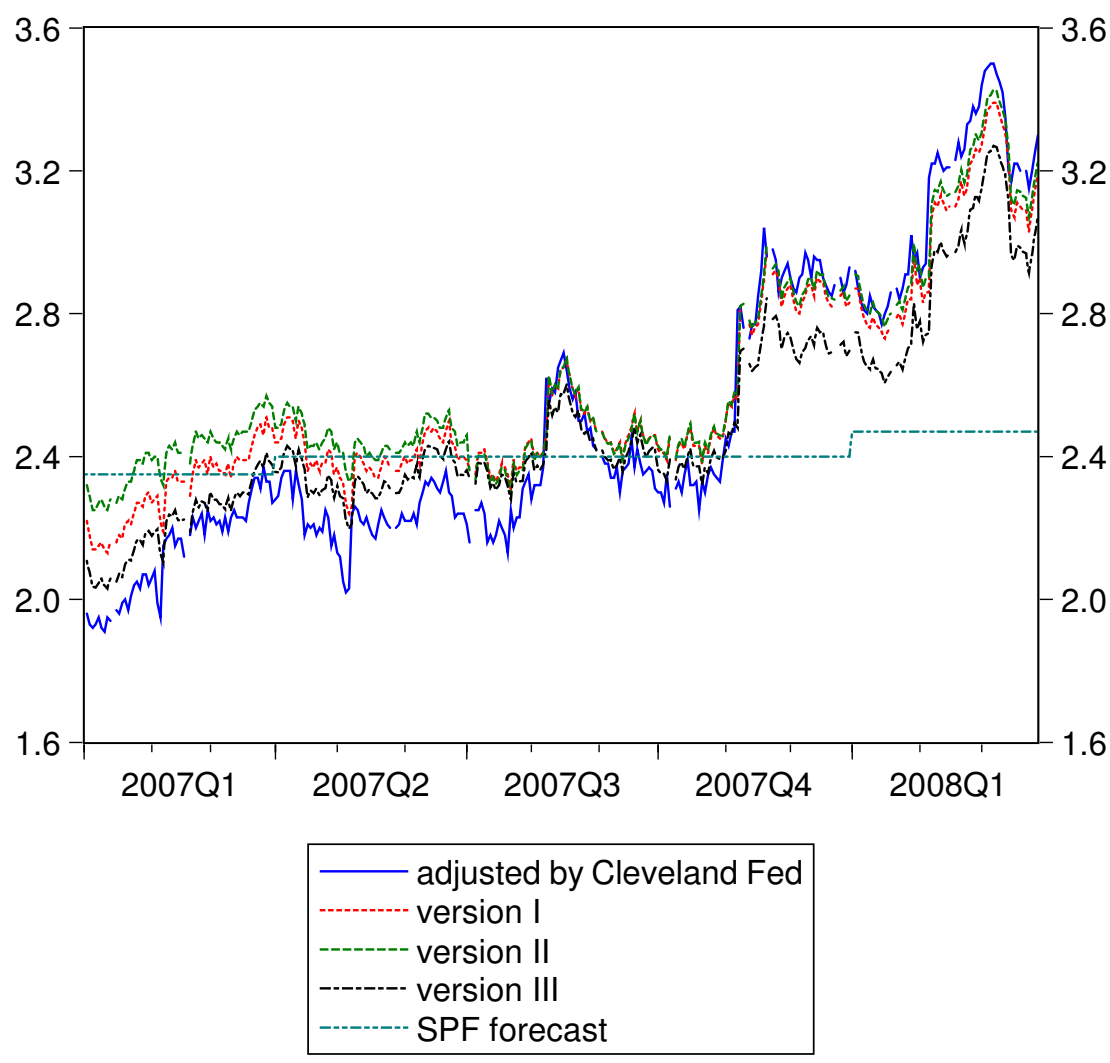

Figure 1: Inflation expectations adjusted for liquidity and inflation risk premia using two different measures for inflation risk. 


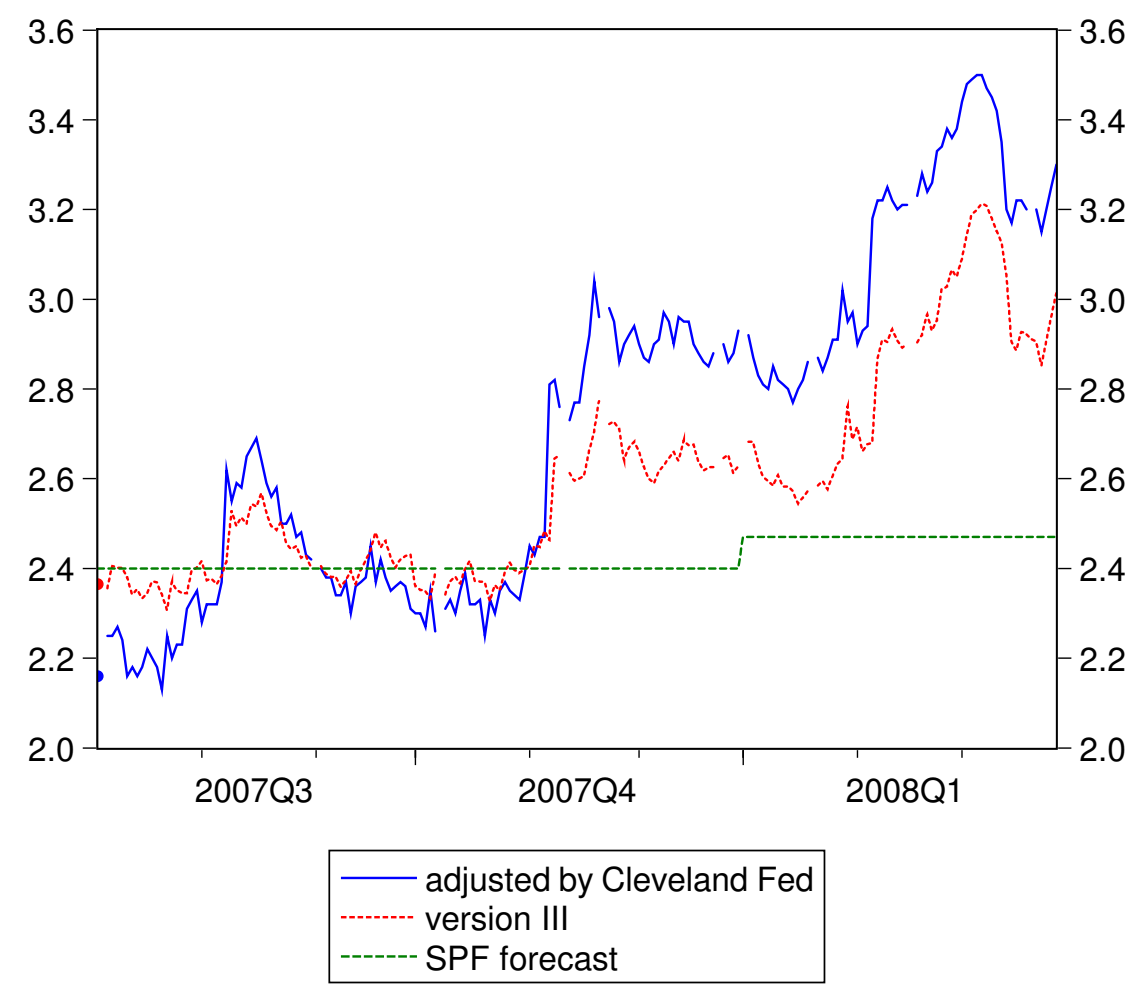

Figure 2: Inflation expectations adjusted for liquidity and inflation risk premia using the conditional volatility of inflation. 


\section{A closer look at the liquidity premium}

The major problem when studying the relationship between the liquidity premium on TIPS and the premium on nominal treasuries is that no data on the former is directly available. In contrast, the liquidity premium on nominal treasuries might be measured by the difference in the yields on on-the-run and off-the-run nominal bonds. The Cleveland Fed assumes that there is a positive and stable correlation between the TIPS liquidity premium and the on/off-the-run premium, and in particular assumes this is given by equations (8) and (6).

\subsection{Liquidity premium on TIPS versus the on/off-the-run premium on nominal bonds}

In order to investigate the relation between the two premia, we take the Cleveland Fed serious and turn their approach upside-down. In other words, we assume the Fed is indeed able to estimate inflation expectations correctly, i.e. $E_{t} \bar{\pi}_{t, t+10}=C F_{t}$, where $C F_{t}$ is the Cleveland Fed's adjusted measure of expected inflation (see equation 9). In addition, we follow the Fed in assuming the inflation risk premium to be constant too, $\rho_{t}^{\pi}=\rho^{\pi}$. These two assumptions allow us to solve equation (3) for the liquidity risk premium of TIPS yields versus nominal Treasuries, i.e. $\rho_{t}^{L P}$. We then relate the series for $\rho_{t}^{L P}$ to $L P_{t}$, the on/off-the-run liquidity premium in the nominal Treasuries market for which data is in fact available. Thus, having data on these two variables allows us to study their relationship given the Cleveland Fed's assumptions were indeed to hold. Figure 3 shows the resulting relationship between the two premia.

The positive and nonlinear relationship is not surprising since it results from the way the Fed calculates the spread $d_{t}$. In other words, if the Fed did not regress the spread $_{t}$ on a linear and quadratic term (see equation 8), the relationship between the two liquidity premia would look linear. To make the exact nonlinear relationship between the two liquidity premia more explicit, we solve equation (3) for the liquidity premium and assume $E_{t} \bar{\pi}_{t, t+10}=C F_{t}$ and $\rho_{t}^{\pi}=\rho^{\pi}$ :

$$
\rho_{t}^{L P}=\rho^{\pi}-B E I R_{t}+C F_{t}
$$

Substituting in for $C F_{t}$ from equation (9) we obtain:

$$
\rho_{t}^{L P}=12.71 L P_{t}-20.9 L P_{t}^{2}
$$

To get a feeling for the true empirical relationship, we use as a second measure for $E_{t} \bar{\pi}_{t, t+10}$ the inflation forecast from the SPF. 


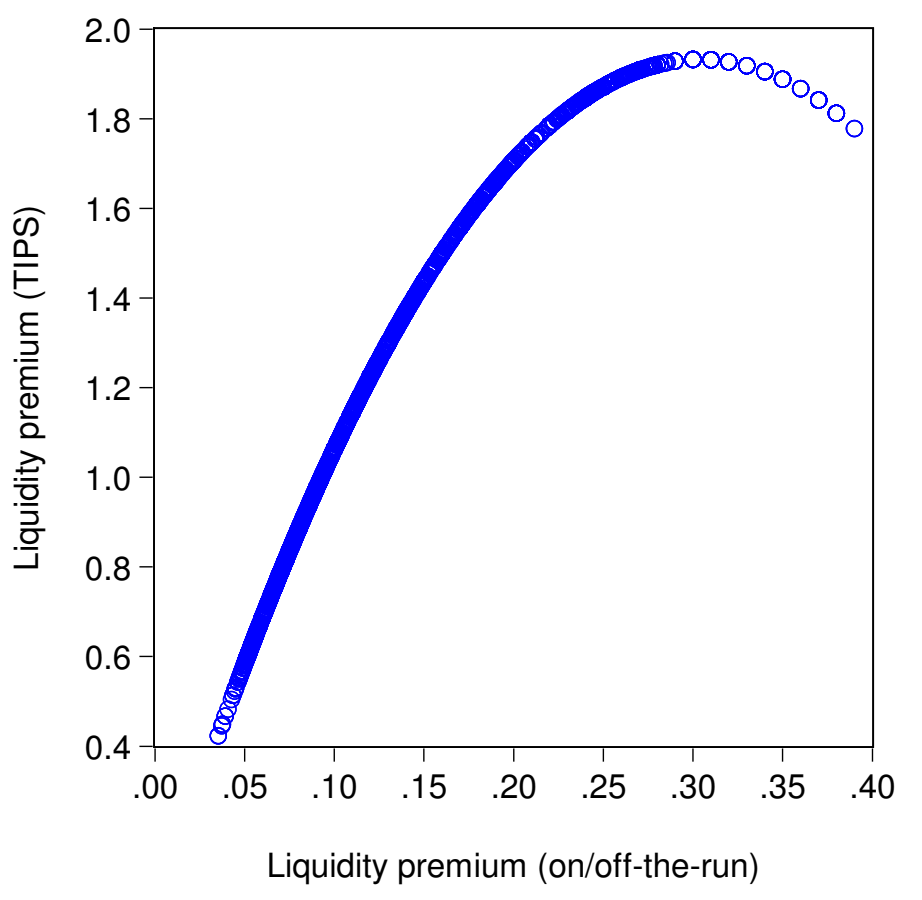

Figure 3: TIPS liquidity premium vs. on/off liquidity premium: The exact nonlinear relationship is by construction because the Cleveland Fed regresses the spread $_{t}$ on linear and quadratic terms of $L P_{t}$. See equation (8). 


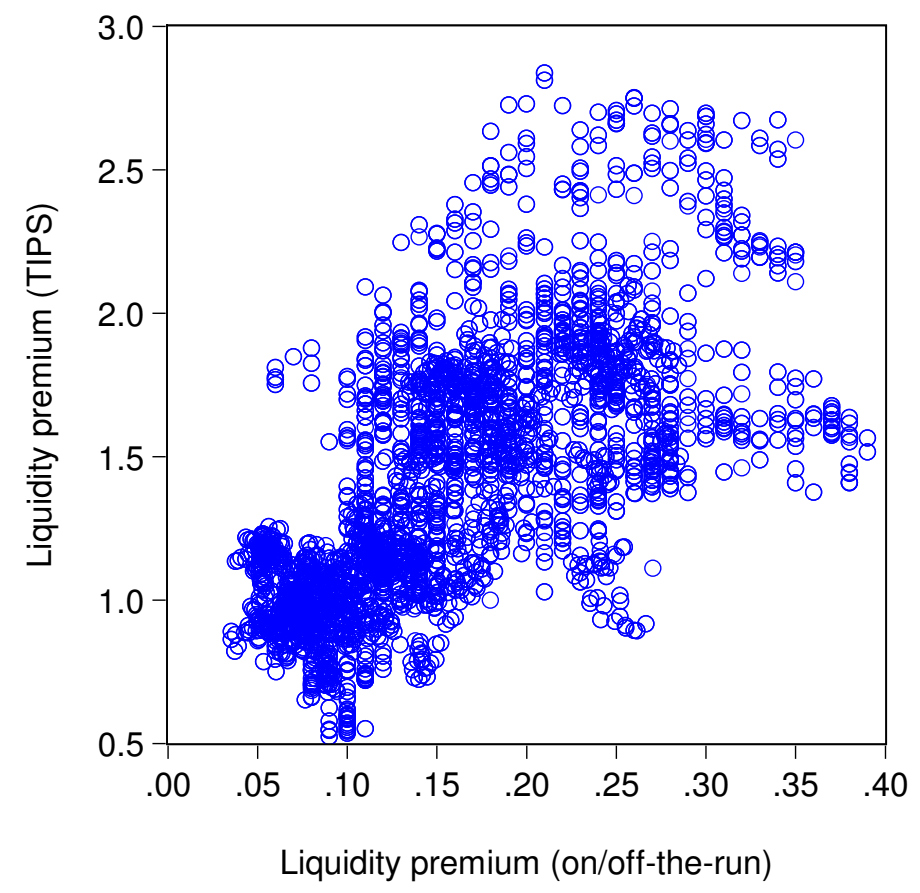

Figure 4: TIPS liquidity premium vs. on/off liquidity premium: The empirical relationship looks linear, but isn't strong and there is no evidence of a nonlinear relationship.

$$
\tilde{\rho}_{t}^{L P}=\rho^{\pi}-B E I R_{t}+S P F_{t}
$$

We again solve for the liquidity premium on TIPS (equation 11) and plot the resulting series in figure 4. Though the figure does reveal some correlation between the two premia, this relation is not very strong and there is no evidence of a nonlinear relationship at all. Rather, there seems to be evidence of heteroskedasticity ${ }^{6}$. However, the fact that the linear relationship is somewhat disturbed might well be caused by, first, a time-varying slope parameter in the spread-regression (equation 8 ) or second, by a time-varying inflation risk premium. The next subsection discusses alternative measures for the TIPS liquidity premium.

\footnotetext{
${ }^{6}$ We account for heteroskedasticity in our estimations by using heteroskedasticity robust standard errors.
} 


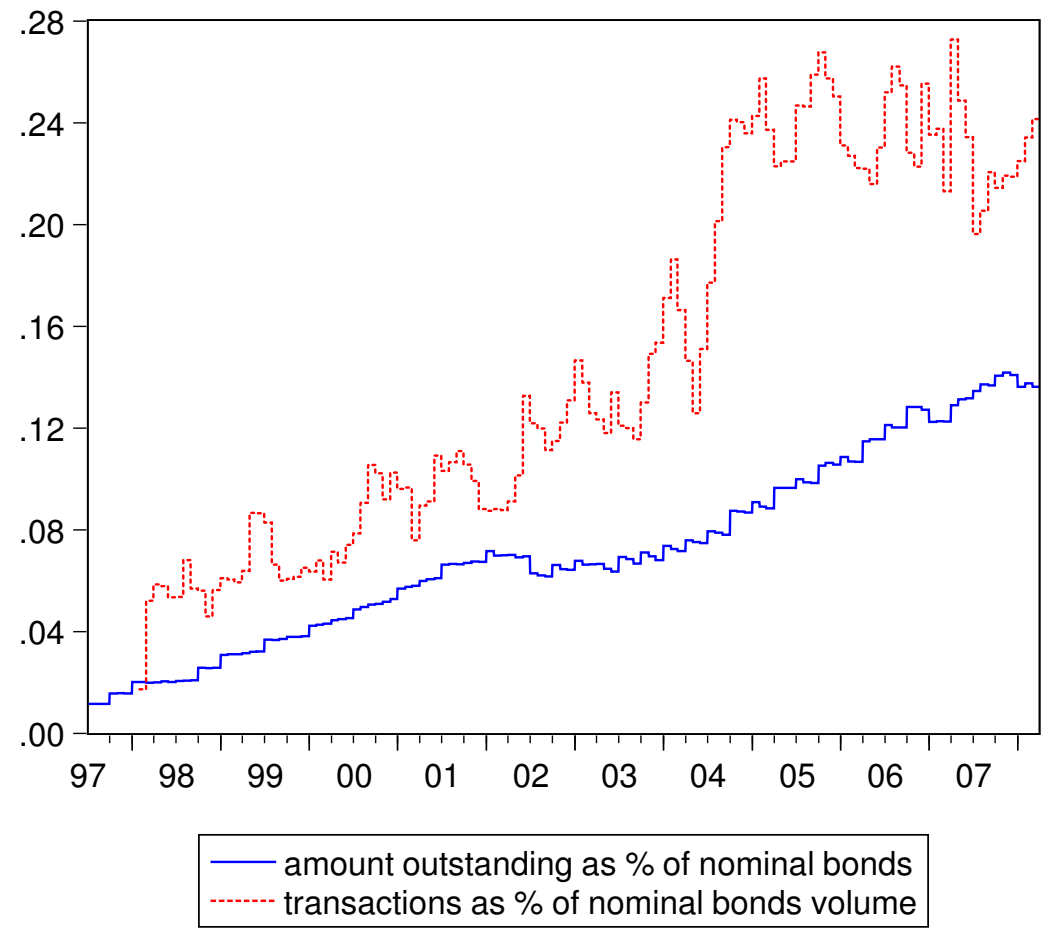

Figure 5: Outstanding TIPS notes of maturity of 5 and 10 years as percentage of nominal treasury bonds with comparable maturity. TIPS primary dealer transactions volume as percentage of transactions volume of nominal treasury bonds with comparable maturity, three month moving average. A higher value indicates a lower TIPS liquidity premium.

\subsection{Measures for the TIPS liquidity premium}

There are potentially more direct measures for the TIPS liquidity premium than $L P_{t}$, e.g. the bid-ask spread, the amount outstanding or the transactions volume in the TIPS market. Data for the latter two are available and are plotted in figure 5 (each as the ratio to the number for nominal treasuries of comparable maturity).

Both series have been increasing over time ${ }^{7}$. A higher value of each series makes the market for TIPS more liquid. Consequently, higher values should be associated with a lower liquidity

\footnotetext{
${ }^{7}$ We disregard any issues arising from potential non-stationarity to make our analysis comparable to the Fed's, who don't account for non-stationarity in their series either.
} 


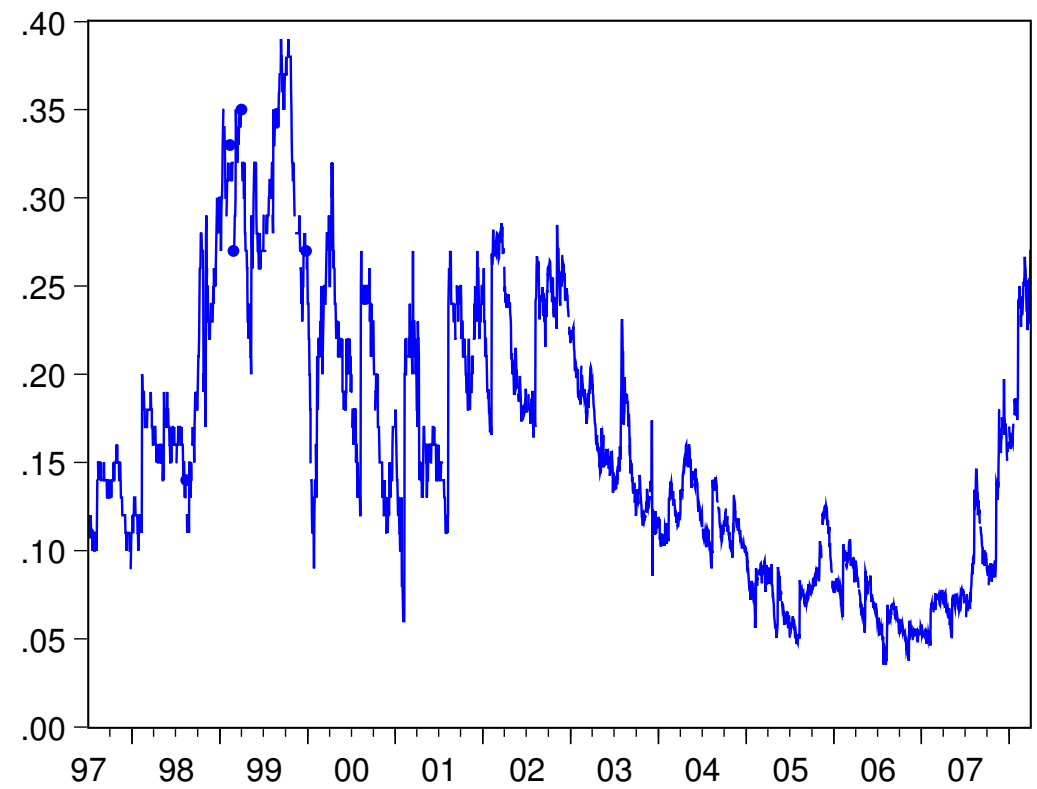

on-/off-the-run spread in nominal treasuries market

Figure 6: Spread between off-the-run and on-the-run nominal treasuries. A higher value indicates a higher nominal bonds liquidity premium.

premium. Note that in particular towards the end of the sample starting from the second half of 2007 the transactions volume rises and the amount outstanding stays roughly constant. This is in contrast to what the on-/off-the-run spread indicates. Figure 6 shows the on-/off-the-run spread on nominal treasuries, which the Fed uses as a measure for the liquidity premium in the TIPS market.

Starting from the second half of 2007 the liquidity premium in nominal on-the-run treasuries has increased, which increased the on-/off-the-run spread. Taking this spread as a measure for the TIPS liquidity premium one might conclude that liquidity in the TIPS market has fallen. However, the transactions volume and the amount outstanding of TIPS convey evidence that TIPS liquidity has not decreased but most likely actually increased. In the next section we explain the consequences of the two opposing views concering the change in the TIPS liquidity premium for inflation expectations. 


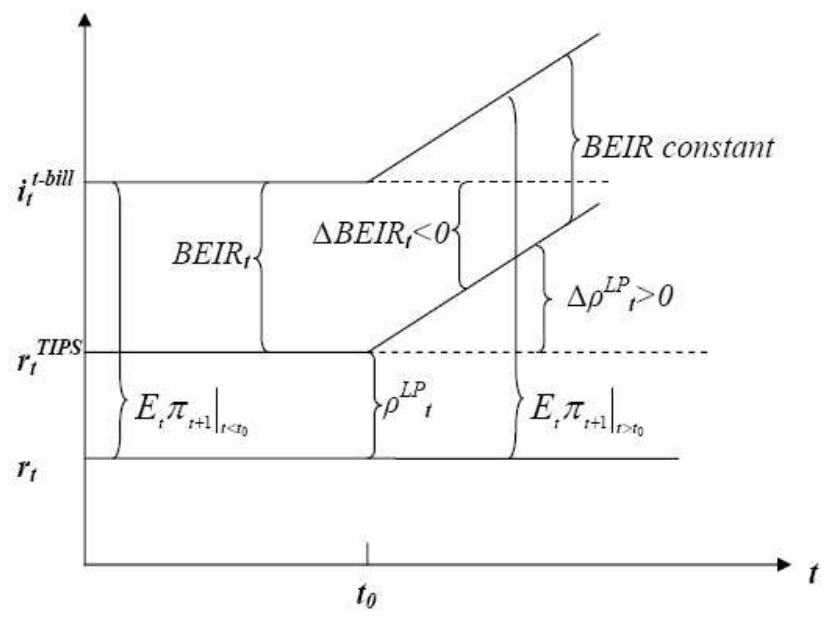

Figure 7: Schematic depiction of the Fisher equation and the effect on expected inflation of an increase in the liquidity premium under the Cleveland Fed assumptions.

\subsection{How are inflation expectations related to the TIPS liquidity pre- mium?}

To illustrate the mechanism behind the Fed and to motivate our own approach consider figure

7. It depicts the unobserved natural real rate $r_{t}$ along with the real TIPS yield $r_{t}^{\text {TIPS }}$ and the nominal T-bill rate $i_{t}^{T-b i l l}$. Under the simplifying assumption of a zero inflation risk premium the difference between the nominal T-bill rate and the unobserved natural real rate equals expected inflation. Furthermore, the difference between the nominal T-bill rate and the real TIPS yield is equal to the BEIR. Lastly, the difference between the real TIPS yield and the unobserved natural rate is the liquidity risk premium.

Now suppose at $t=t_{0}$ the liquidity risk premium rises by $\Delta \rho_{t}^{L P}>0$ and keeps constantly rising, as the Cleveland Fed argues happend from August 2007 on. This increases the real TIPS yield by the same amount. Under the assumption of a constant natural real rate the effect on expected inflation depends on the behaviour of the BEIR. In the special case where the BEIR stays constant expected inflation rises exactly by the change in the liquidity premium. In any other case the effect on expected inflation depends on the change in the nominal t-bill rate. Even if the natural real rate is not constant, the correlation between the liquidity risk premium and 


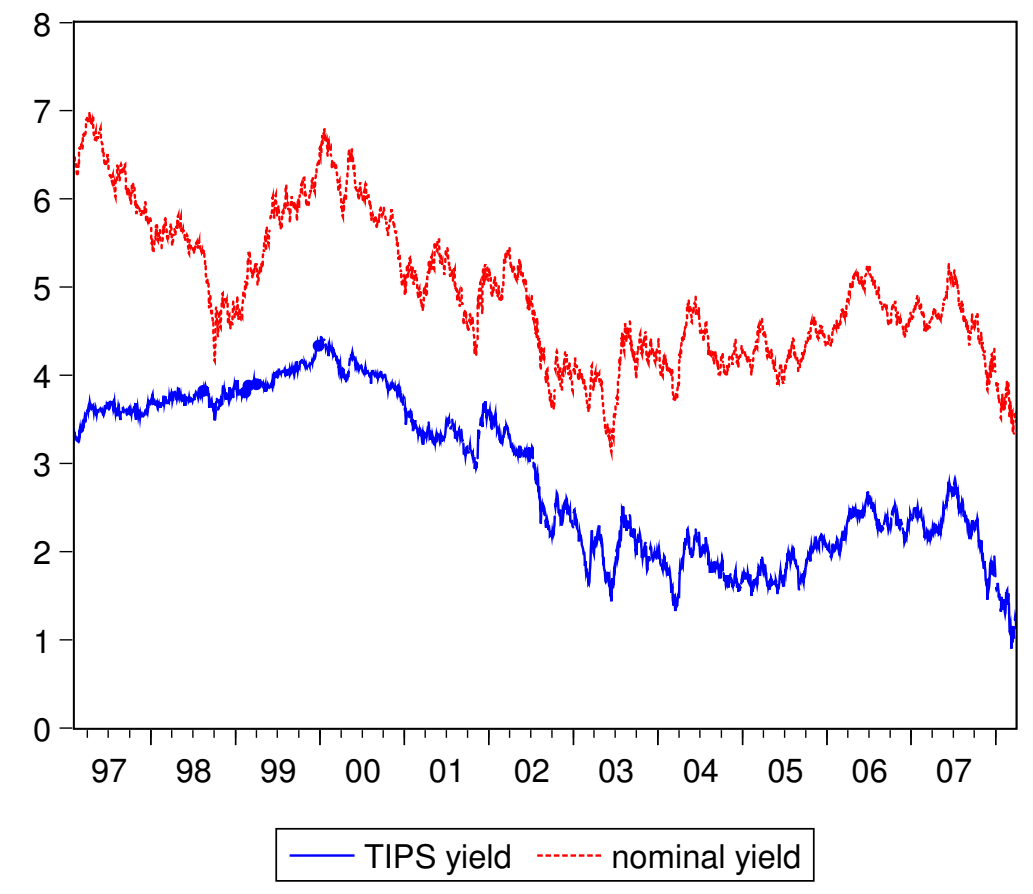

Figure 8: Nominal treasury yield and real TIPS yield. The difference is equal to the BEIR. Towards the end of the sample the TIPS yield falls but the BEIR stays roughly constant.

expected inflation depends on the change in the BEIR, as can be seen from the Fisher-equation.

To find out which case the data support we plot the TIPS yield together with the nominal yield in figure 8. The difference between the two lines is the BEIR. Observe that the TIPS yield has fallen towards the end of the sample and the BEIR has stayed roughly constant. Taken together with the observations from figure 5 the data rather suggest that the TIPS liquidity premium has fallen as opposed to what a measure based on the on-/off-the-run spread would tell. In that case expected inflation would fall. The explanation for why the nominal yield spread between on-/off-the-run securities has risen while the TIPS liquidity premium has fallen might lie in the flight-to-quality-phenomenon. The problems in financial markets starting in August 2007 led to an increased demand for nominal U.S. treasury bonds which resulted in an increase in the on-/off-the-run spread. However, it is plausible that trading in TIPS increased as well, which is supported by the data. Therefore TIPS are likely to have gained in liquidity at the 


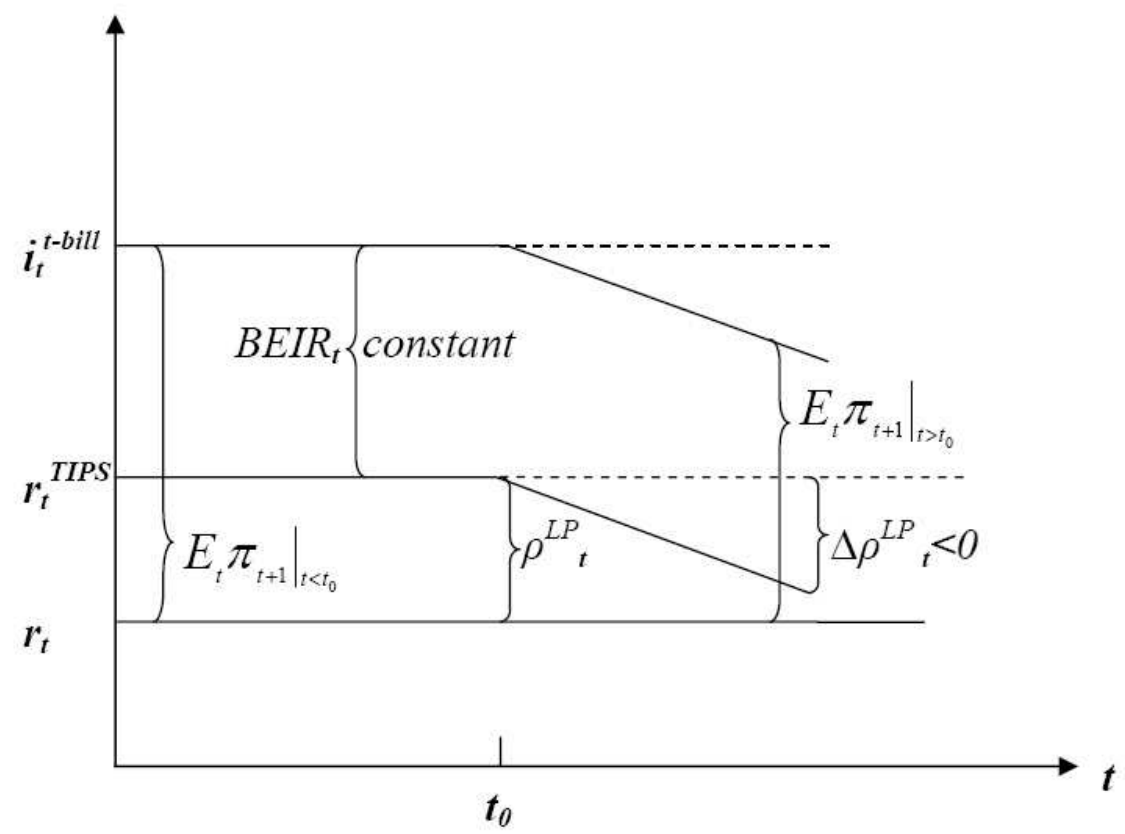

Figure 9: Schematic depiction of the Fisher equation and the effect on expected inflation of a decrease in the liquidity premium.

same time as the on-/off-the-run spread in nominal treasuries has risen. We illustrate the case of a falling TIPS liquidity premium with a resulting fall in expected inflation in figure 9 .

It is important to note that up to here a constant inflation risk premium was assumed. Letting it vary over time adds another variable to the Fisher equation, which could partly offset the response of expected inflation to an increase/decrease in the liquidity premium for a given change in the BEIR. Our results in section 5 will show exactly this result: Using the on/offthe-run liquidity premium we find that it is the inflation risk premium which has increased since August 2007, thus almost entirely compensating the observed increase in the Cleveland Fed adjusted inflation expectations series. Not accounting for this increase in the inflation risk premium thus leads the Cleveland Fed now to overstate actual inflation expectations.

To quantify the effects on the adjusted measure of expected inflation according to the Cleveland Fed approach we repeat their adjustment method making use of the transactions volume in the TIPS market as measure for the TIPS liquidity premium. We re-estimate equation (10). However, we use the ratio of transactions volume of TIPS to the one of nominal treasuries, 
volume, as a measure for the TIPS liquidity premium. Note that the expected sign on the coefficient $\beta_{1}$ in (10) is now positive because a higher transactions volume decreases liquidity risk and the premium, which in turn is associated with a higher spread. The spread regression now yields

$$
\widehat{\text { Sprea }_{t}}=-1.22+6.05 \text { volume }_{t}-4.24 \text { volume }_{t}^{2}
$$

The coefficients are all significant on the $1 \%$-level, except for the squared term, which is significant on the 5\%-level. What is peculiar is the negative constant. However, a plot of the resulting adjusted series for expected inflation yields plausible results. Figure 10 plots our adjusted measure for expected inflation using the TIPS transactions volume as a measure for TIPS liquidity risk. Clearly expected inflation is much lower at the end of the sample than estimated by the Fed.

Adding the conditional volatility of inflation as a measure for an inflation risk premium results in

$$
\widehat{\text { Sprea }_{t}}=-1.23+6.02 \text { volume }_{t}-4.21 \text { volume }_{t}^{2}+0.02 I P_{t}
$$

However, the coefficient on the inflation risk premium is economically and statistically insignificant.

This section has demonstrated that it is crucial which measure one uses to estimate the TIPS liquidity premium. Especially during the times of the recent financial turmoil different measures convey different stories. The spread between on-/off-the-run nominal bonds has increased while the transactions volume in the TIPS market relative to the nominal bonds market has increased.

Up to here we have followed the Cleveland Fed approach and have evaluated their measures for the different risk premia. In the following section we tackle the problem of how to get away from survey based measures and present an alternative approach.

\section{Using a state-space approach to estimate inflation ex- pectations}

As an alternative approach to model, estimate, and predict inflation expectations using yield data on TIPS we employ a state-space framework. This has been shown to work well for the estimation 


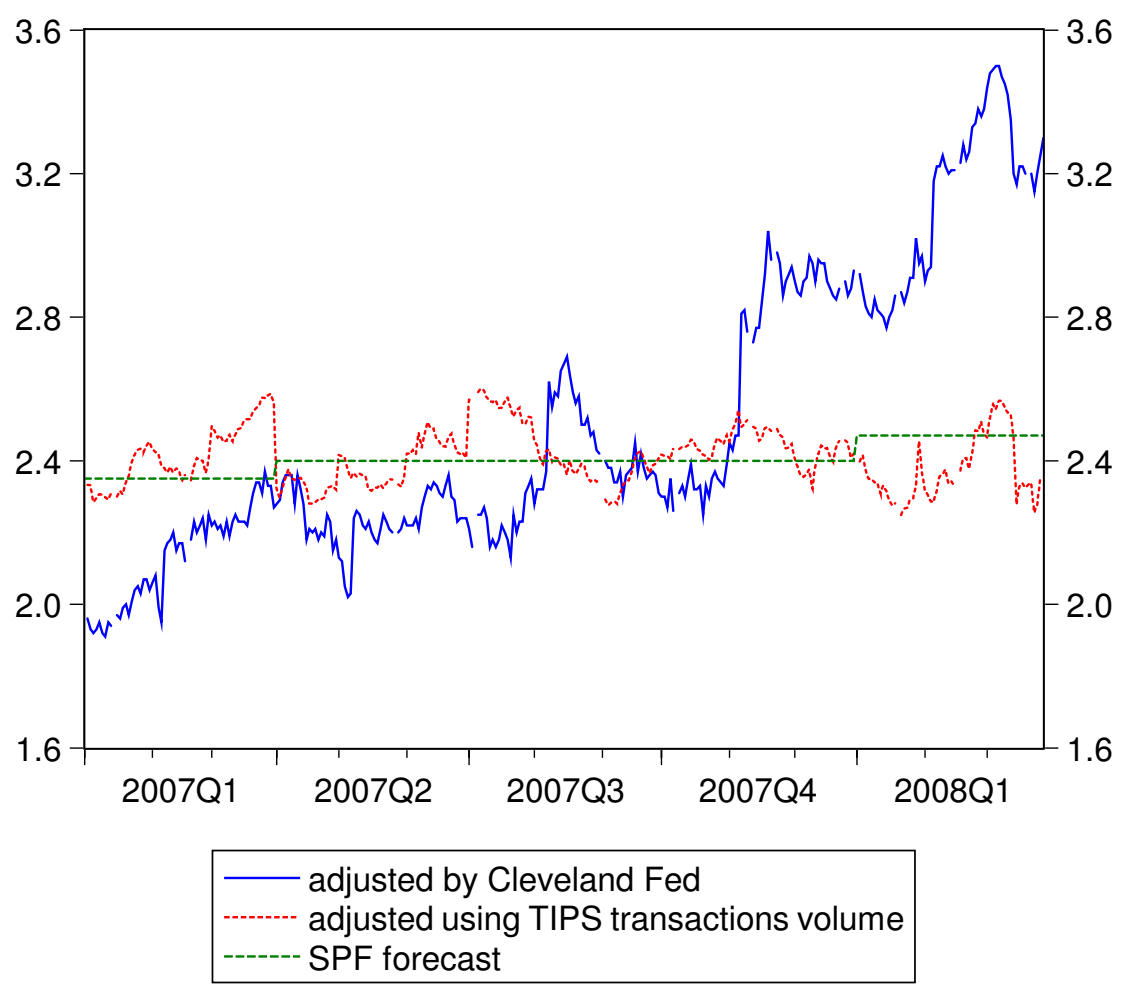

Figure 10: Adjusted inflation expectations using the TIPS transactions volume as measure for TIPS liquidity risk compared to Fed adjustment and SPF forecast. 
of ex ante real interest rates as e.g. shown in Hamilton (1994). Our approach acknowledges that inflation expectations, as well as the relevant risk premia are inherently unobservable and models them in a standard state-space framework, that allows us to derive inflation forecasts that are completely free of any survey-based measure. In this section we provide the details of the econometric modelling of our proposed state-space model:

$$
\begin{aligned}
z_{t+1} & =F z_{t}+v_{t+1} \\
y_{t} & =H z_{t}+w_{t}
\end{aligned}
$$

with following unobservable state variables: $E_{t} \pi_{t+1}$ expected inflation, $\rho_{t}^{\pi}$ the inflation risk premium, and $\rho_{t}^{L P}$ the liquidity risk premium.

$$
z_{t}=\left(\begin{array}{c}
E_{t} \bar{\pi}_{t \mid t+10} \\
\rho_{t}^{\pi} \\
\rho_{t}^{L P}
\end{array}\right)
$$

and the following observable variables:

$$
y_{t}=\left(\begin{array}{c}
i_{t}^{T-B i l l}-r_{t}^{T I P S} \\
\sigma_{t}^{\pi} \\
L P_{t}
\end{array}\right)
$$

where $i_{t}^{T-B i l l}-r_{t}^{T I P S}$ is the unadjusted BEIR time series obtained by subtracting the real yield on TIPS from the corresponding nominal rate. $\sigma_{t}^{\pi}$ is our GARCH-based measure for inflation volatility which we argue is a good indicator for the uncertainty surrounding inflation expectations. ${ }^{8}$ It seems pretty natural to then relate the unobservable inflation risk premium to our series of inflation forecast uncertainty. Finally, $L P_{t}$ is the on/off-the-run liquidity premium from the nominal Treasuries market defined in equation (7).

In the model (16) we then impose some structure on the coefficient matrices by making use of the arbitrage condition between nominal and real returns: ${ }^{9}$

$$
i_{t}^{T-B i l l}-r_{t}^{T I P S}=E_{t} \bar{\pi}_{t \mid t+10}+\rho_{t}^{\pi}-\rho_{t}^{L P}
$$

${ }^{8} \mathrm{We}$ also used as a measure of uncertainty around inflation expectations the standard deviations of forecasts of inflation from the Survey of Professional Forecasts. Whilst both series reveal the same message, we prefer our GARCH-based measure of uncertainty of inflation expectations because of its monthly, as opposed to quarterly frequency.

${ }^{9}$ See equation (3) above. 
We add an error term to equation (17) to allow for transitory noise in the arbitrage relationship resulting from possible frictions in financial markets.

We impose further structure on model (16) by assuming autoregressive processes for the inflation risk and liquidity risk premia, and by assuming inverse functional relationships between the observable measures of risk/volatility and the corresponding risk premia. In other words, whilst it is standard practise to assume that risk premia depend on measures of risk and volatility, we turn this relationship upside down and assume a unique inverse relationship exists, i.e. that the observables are linear functions of the states. ${ }^{10}$ The model is closed by assuming the error terms are normally distributed white-noise.

We then use a Kalman-Filter approach to estimate the following $F$ and $H$ matrices together with the variances of the error terms:

$$
\begin{aligned}
& F=\left[\begin{array}{ccc}
f_{1} & 0 & 0 \\
0 & f_{2} & 0 \\
0 & 0 & f_{3}
\end{array}\right] \\
& H=\left[\begin{array}{ccc}
1 & 1 & -1 \\
0 & h_{1} & 0 \\
0 & 0 & h_{2}
\end{array}\right]
\end{aligned}
$$

Our approach offers a number of advantages over the Cleveland Fed approach. Instead of again relying on a survey-based measure of inflation expectations in calculating the bias in the unadjusted BEIR series, we do not resort to surveys. Instead, we treat inflation expectations, as well as the relevant risk premia as inherently unobservable - which they undoubtedly are. We employ a simple state-space model in which we linearly relate the observable measures of inflation compensation and uncertainty to the unobservable expected inflation which we are ultimately interested in, as well as the risk premia for liquidity and inflation. The model (16) is estimated through a standard Kalman filter algorithm. Whilst the state-space model potentially allows for a large number of free parameters and hence, for very general specifications, we restrict ourselves to what we believe to be a simple, parsimonious, and economically reasonable specification.

The results of our state-space model are shown in figure 11. We plot the smoothed stateseries: the inflation forecast, the liquidity risk and the inflation risk premium together with the

\footnotetext{
${ }^{10}$ More general nonlinear functional specifications are possible, but need much more complicated and computationally-intensive solution algorithm. Whilst this is an interesting possibility to improve on our results, we believe the current model specification is sufficient to highlight our main points of departure and improvements over the Cleveland Fed approach.
} 


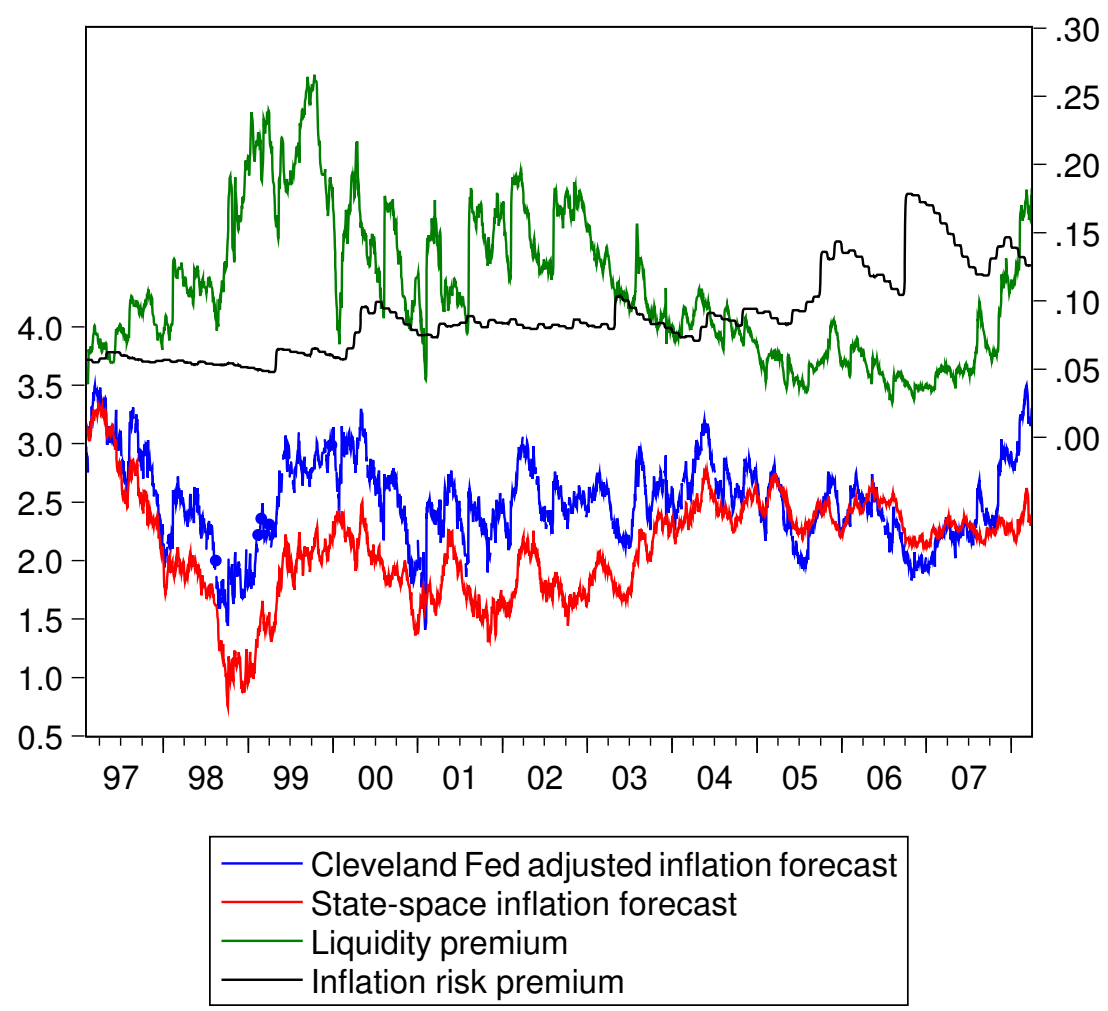

Figure 11: Smoothed time series from the state-space model and Cleveland Fed adjusted inflation forecast: Cleveland Fed and state-space inflation forecast rising towards the end of the sample. State-space forecast, however, at lower level. 
adjusted Cleveland Fed measure for inflation expectations. There is a strong rise in inflation expectations of the Cleveland Fed series at the end of the sample. In constrast the state-space inflation forecast series - in line with the arguments of section 3 - picks up much less at the end of the sample.

Our method also allows us to back out the liquidity and inflation risk premia as smoothed estimates from the Kalman filter procedure. Interestingly, we see a gradual rise in the inflation risk premium at the end of the sample. However, having studied the univariate properties of the data series, the results have to be treated with caution given the strong evidence of non-stationary behaviour in the series.

Finally, to compare our approach and results with the Cleveland Fed's we highlight again the implied relation between inflation expectations and the liquidity premium. Figure 12 plots a scatter of our measures of inflation expectations and the liquidity premium. The correlation is now negative, with a coefficient of -0.57 . This results from the unconditional nature of the plot: In other words, the other variables in the Fisher equation are also changing. Because our approach allows for a variable inflation risk premium, the resulting unconditional correlation between the expected inflation series and the liquidity premium no longer has to be positive, but now turns negative. The inflation risk premium and the BEIR are moving in the background too. Our results in fact suggest the liquidity premium is negatively related to the inflation risk premium. In other words, our results strongly suggest that it is the BEIR that adjusts to bring the variables back into Fisher-equilibrium. The two premia alone would instead cause deviations from the Fisher-equation.

\section{Conclusion}

In this paper we aimed at understanding how one should optimally correct inflation-expectations derived from TIPS yields for time-varying liquidity and inflation risk premia. Starting from an approach by the Cleveland Fed we have shown that, first, their method yields on average the inflation forecast of the Survey of Professional Forecasters, second the relation between the unobserved liquidity risk premium and measures for the liquidity risk premium in nominal treasuries is likely not constant over time, and third the assumption of a constant inflation risk premium is not innocuous with respect to the estimated adjusted inflation expectations. In particular, once we account for a time-varying inflation risk premium the adjusted figures for expected inflation are considerably lower. In addition we propose as an alternative approach 


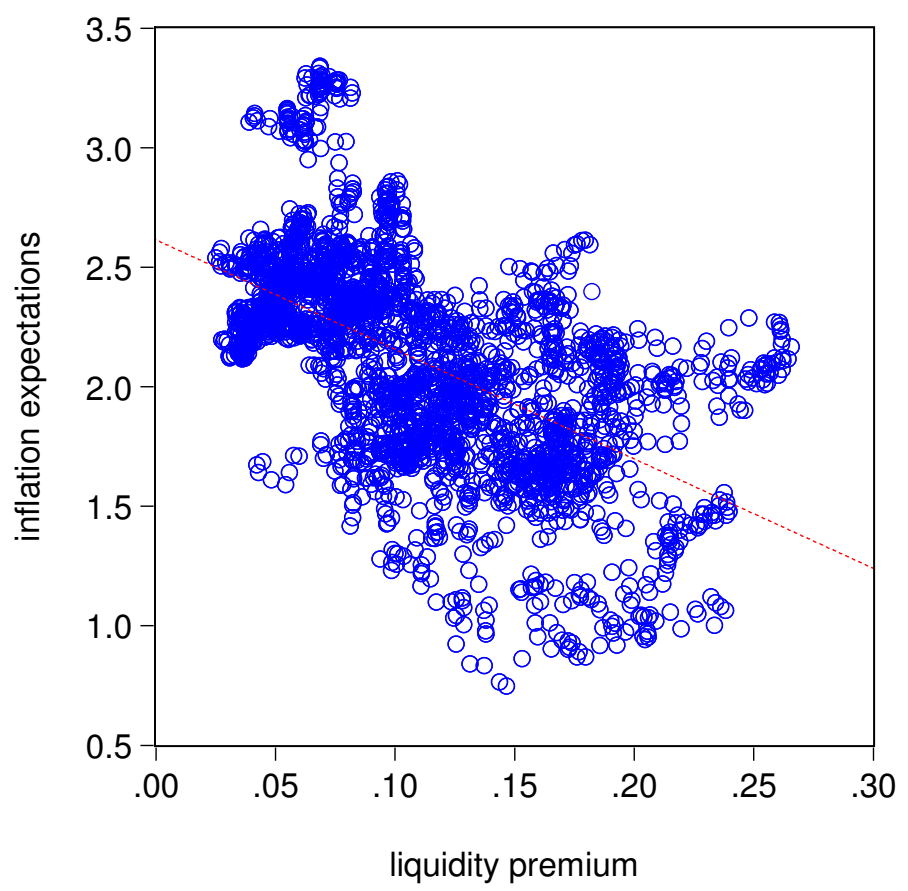

Figure 12: Our state-space model predicts a negative relation between inflation expectations and liquidity risk premia. The BEIR instead adjusts. 
a state-space estimation of the liquidity premium, the inflation risk premium and expected inflation. This approach, which is entirely market-based, also yields lower current inflation expectations.

\section{References}

[1] Amico, S., D. Kim and M. Wei (2008): Tips from TIPS: the informational content of treasury inflation-protected security prices. BIS Working Paper No. 248.

[2] Fisher, M. (2002): Special repo rates: an introduction. Economic Review, second quarter, Federal Reserve Bank of Atlanta.

[3] Garcia, J. and A. van Rixtel (2007): Inflation-linked bonds from a central bank perspective. ECB Occasional Paper No. 62.

[4] Hamilton, J. D. (1994): Time Series Analysis, Princeton.

[5] Hördahl, P. and O. Tristani (2007): Inflation risk premia in the term structure of interest rates. ECB Working Paper No. 734.

[6] Sack, B. and R. Elsasser (2004): Treasury inflation-indexed debt: a review of the U.S. experience. Economic Policy Review, May, Federal Reserve Bank of New York.

[7] Shen, P. (2006): Liquidity risk premia and breakeven inflation rates. Economic Review, second quarter, Federal Reserve Bank of Kansas City.

[8] Vayanos, D. and P. Weill (2006): A search-based theory of the on-the-run phenomenon. NBER Working Paper No. 12670.

\section{Appendix}

This appendix shows why the adjustment method used by the Cleveland Fed on average leads to the survey result obtained by the Survey of Professional Forecasters (SPF). In other words, we show that the essential advantage of the Fed-measure of inflation expectations is not its perceived independence from survey results, but only the higher frequency for which inflation forecasts are possible using this method. 
We assume the SPF publishes every month $t$ a forecast of average annual inflation over the next 10 years. We denote this survey-based inflation forecast with $S P F_{t}$ where the subscript here and in what follows always indicates the time at which the forecast is made. In other words, $S P F_{t}$ denotes the inflation forecast of the SPF made at time $t$ for the average annual inflation rate over the following 10 years. From equation (5) in the text we know that the Fed calculates on each day $t+j$ the "spread" as difference between the unadjusted BEIR at time $t+j$ and $S P F_{t}$. Formally, we have the following:

$$
\text { spread }_{t+j}=B E I R_{t+j}-S P F_{t} \quad j=0,1,2, . ., 29
$$

As laid out in section 2, the Fed then regresses this spread on a constant and a linear and squared measure of the liquidity premium. The Fed then takes the predicted values from this regression and subtracts them from the unadjusted BEIR to derive its measure of adjusted TIPS-derived inflation expectations $C F_{t+j}$. Formally, this is given as:

$$
C F_{t+j}=B E I R_{t+j}-\widehat{\text { spread }}_{t+j}
$$

To show that the average value of the Cleveland Fed inflation forecasts $C F_{t+j}$ equals the SPF-forecast, we average out the daily Cleveland Fed forecasts over the month in which the SPF forecast was announced.

$$
\begin{aligned}
\frac{1}{30} \sum_{j=0}^{29} C F_{t+j} & =\frac{1}{30} \sum_{j=0}^{29}\left(B E I R_{t+j}-\widehat{\text { spread }}_{t+j}\right) \\
& =\frac{1}{30} \sum_{j=0}^{29}\left(B E I R_{t+j}-\left(\text { spread }_{t+j}-u_{t+j}\right)\right) \\
& =\frac{1}{30} \sum_{j=0}^{29}\left(S P F_{t}+u_{t+j}\right) \\
& =\frac{1}{30} 30 S P F_{t}+\frac{1}{30} \sum_{j=0}^{29} u_{t+j} \\
& =S P F_{t}+\frac{1}{30} \sum_{j=0}^{29} u_{t+j}
\end{aligned}
$$

